\title{
Vegetative Propagation of Deciduous Rhododendrons using Root Stimulating Agents
}

\author{
Z.I. Smirnova ${ }^{*}$, and I.A. Bondorina \\ Main Botanical Garden named after N.V. Tsitsin RAS, 127276 Moscow, Russia
}

\begin{abstract}
The genus Rhododendron $\mathrm{L}$. is the largest in the heather family Ericaceae DC. Rhododendrons are decorative evergreen, semi-evergreen and deciduous shrubs that have gained great popularity in green building, ornamental gardening and breeding. Among all groups of rhododendrons, deciduous are the most promising for cultivation in Central Russia due to their high winter hardiness, unpretentiousness and exceptional decorative effect. The article presents the results of experiments carried out at the GBS RAS in 2017-2020 on vegetative propagation of 50 species and varieties of deciduous rhododendrons. Vegetative propagation of deciduous rhododendrons is a rather laborious long process. Cutting deciduous rhododendrons has its own nuances and is considered problematic. In this regard, the selection of optimal conditions for the propagation of rhododendrons, which can enrich the cultural flora of the North-West, central Russia, the Urals and Siberia, was the main goal of this work.
\end{abstract}

\section{Introduction}

The history of rhododendron culture dates back more than 300 years and is closely related to the history of introduction. In nature, they are common in regions with moderate and cool climates. In world horticultural practice, in the years since of C. Linnaeus, only evergreen species were called rhododendrons, and deciduous species were called azaleas, and only after the publication of G. Don (1834), deciduous and evergreen rhododendrons have been assigned to the genus Rhododendron. Representatives of the genus include about 1,300 species and more than 12,000 varieties [1].

Unfortunately, in Russia, rhododendrons are still uncommon in culture, an obstacle to this is low winter temperatures, insufficient rainfall in summer, dry air during the blooming period.

The lighting conditions for rhododendrons are quite varied. They grow both in full sunlight and can form undergrowth in half shade. The optimal conditions for their growth are light, acidic soils rich in organic matter and an equable climate. The root system is very compact; therefore, drainage and aeration are essential [2].

Evergreen rhododendrons are widespread in Russia [1]. These are usually large bushes with large leather-like leaves that persist on plants even in winter. The major difficulty in

\footnotetext{
* Corresponding author: zsmir8@mail.ru
} 
growing them lies in the preservation of the leaf apparatus in winter and protection from parching winds and spring sun scalds. Hence, there are additional requirements for the planting site, caring for them. In Russia, there are about 44 species of evergreen rhododendrons, and only half of them are winter hardy, the rest of the species and varieties are weakly hardy and, therefore, can grow only in the Northwest region, the Far East (Primorye), and the Black Sea coast of the Caucasus [1].

Half-evergreen rhododendrons are usually small bushes $(50-60 \mathrm{~cm})$, which allows them to winter under the snow. The flowering is abundant, but they often rot. Only 5-6 species are recognized as winter-hardy, the rest are slightly winter-hardy.

The third group of plants is represented by deciduous rhododendrons. They require optimal growing conditions and grow slowly in the first years after planting. These are dense, compact bushes, 0.6 to $1.0 \mathrm{~m}$ in height in species and 1.0 to $1.8 \mathrm{~m}$ in hybrids. During flowering, (May-June) the bushes are completely covered with flowers, which make the leaves practically invisible. Flowers are large, collected in inflorescences from 2 to 20 , have the shape of a bell or a bowl, $7-10 \mathrm{~cm}$ in diameter, aromatic, with a wide array of bright shades or their combinations - white, yellow, beige, orange, red and purple, sometimes bright spots in the neck of a flower. Inflorescences practically do not suffer from rain and dew. In the fall, the leaves turn bright colors ranging from yellow to blood red. Deciduous rhododendrons are resistant to diseases and pests [1,2,3]. Another very valuable and important property of deciduous rhododendrons is their high winter hardiness - the ability to withstand thaws, early frosts in late fall and early winter, resistance to rotting, with deep snow cover. Average frost resistance, depending on the varieties, ranges from $\left(-25^{\circ} \mathrm{C}\right.$ to $\left.-30^{\circ} \mathrm{C}\right)[6]$.

The most interesting for research is the group of deciduous rhododendrons Knap Hill Hybrid (Exbury, Knap Hill, Slocock Hybrid). The purpose of our experiment was to test and analyze the ability to vegetative propagation of as many varieties of deciduous rhododendrons as possible using root stimulating agents. The objective of the work was to expand the range of varieties of deciduous rhododendrons that can successfully grow in Central Russia and be widely used in gardening and landscaping.

\section{Materials and methods}

This experimental work on the propagation of deciduous rhododendrons by cuttings using physiologically active substances was carried out at the MBG RAS from 2017 to 2020. The work included 50 varieties of deciduous rhododendrons of the Knap Hill Hybrid group of hybrid origin. This group of hardy varieties was created in the late 19th century in Great Britain. During hybridization the following species were used: Rh. calendulaceum (Michx) Torr., Rh. occidentale (Torr.et A. Gray), Rh. japonicum (Gray)Suring, Rh. molle (G.Don), Rh. arborescens (Pursh) Torr.

Upper half-lignified cuttings of this year were taken as cuttings, from maternal plants in mid-June. By this time, they are already growing ripe and should manage to take root in the summer of the same year. Cuttings of $6-10 \mathrm{~cm}$ in size were taken, the lower leaves were removed, and the upper ones were cut off by one third. The lower part of the cuttings was incised 1-2 cm under the bud, after which they were bunched up on varieties and variants - $\mathrm{K}$ (control) and $\mathrm{O}$ (experiment). The experimental variants were treated with various stimulants at different concentrations and at different exposures, while the controls were not treated. Three types of stimulants were used in the experiment. Experience has shown that the most effective root adjusting agent are indole butiric acid, indoleacetic acid (heteroauxin), succinic acid, and other stimulants [10]. The preparation used in 2018 was indole butyric acid (IBA), a well-known root stimulating agent. In our experiment, two concentrations were taken: IBA solution $(0.05 \%)$ with an exposure of 6 hours, IBA 
solution $(0.01 \%)$ with an exposure of 16 hours [9]. In 2019, the UK-made Clonex rooting hormone, which contains 4-(indol-3-yl)butyric acid at a concentration of 3\% + a vitamin complex, was used. The preparation is a violet-colored gel, into which the roots of the cuttings rooted were $1-2 \mathrm{~cm}$ immersed and then planted in boxes with a specially prepared substrate. Most wild-growing rhododendrons grow well on acidic soils, the reaction of which is $\mathrm{pH}$ 4.5-5.5. Previously, many researchers have tested various combinations of mixtures when formulating substrates for rooting rhododendrons. A substrate is recognized optimum if it consists of acidic peat ( $\mathrm{pH}-4.7)$, sand and leafy soil in a ratio of 2:1:1. Such a mixture provides rooting cuttings with nutrients $[1,2,7]$. In our experiment, the substrate was a mixture of bog peat ( $\mathrm{pH} 3.5-4.0)$, humus and sand in a ratio of 2:1:1, sprinkled on top with a $3 \mathrm{~cm}$ layer of perlite. The boxes were covered with Svetlitsa light-transmitting film and placed in plastic greenhouses, controlling the humidity of the environment.

\section{Results and Discussion}

Vegetative propagation of deciduous rhododendrons is a rather laborious and timeconsuming process [5]. When recommending new varieties, it is necessary to pay attention not only to decorativeness, winter hardiness, but also to the ability to reproduce in cuttings. Cutting deciduous rhododendrons has its own nuances and is considered quite problematic. The growth of this year is taken for cuttings, when the vegetative bud is still growing; therefore it is very important to be right on the period of taking half-lignified cuttings from the maternal bush. Under favorable conditions, secondary roots are formed on the lower part of the cutting. However, in far too many varieties, the formation of roots is difficult; therefore, the rooting rate of cuttings, especially deciduous species and varieties of rhododendrons, is the object of a detailed study of many investigators [8]. The cuttings taken should manage to take root and form new shoots during the same summer. This is very important for the future overwintering, because without new cuttings, cuttings typically die. Since cuttings of rhododendrons are poorly rooted, a need to use additional root stimulating agents arises.

Experiments previously carried out at the MBG RAS on cuttings using physiologically active substances that stimulate the processes of root formation have shown that various types of rhododendrons, evergreen, half-evergreen and deciduous, react completely differently to treatment. So, according to Plotnikova L.S. and Khromova T.V. [4] evergreen Rh.Smirnovii Trautv., Rh. kotschyi Simk., Rh. aureum Georgi, did not take root when using IBA solution $(0.01 \%)$ with an exposure of 16-24 hours, half-evergreen Rh.ledebourii Pojark showed $75 \%$ rooting of cuttings without treatment, and Rh. sichotense Pojark. - did not take root when treated with IBA solution $(0.01 \%)$, deciduous $R h$. davuricum L., untreated 100\% rooting, Rh. japonicum (Gray) Suringar untreated - 33\% rooting, $R h$. kamtschaticum Pall. when treating IBA solution (0.01\%) for 16 hours - 0\%, Rh.luteum Sweet without treatment $-0 \%, R h$. mucronulatum Turcz. when using IBA- $0.01 \%$ and YA (succinic acid) $-0.002 \%$ showed $100 \%$ rooting, Rh. schlippenbachii Maxim. with or without treatment - $0 \%$ rooting, Rh. tschonoskii Maxim. treatment with IBA solution $(0.01 \%)$ gave $0 \%$ rooting. These conflicting data suggest that the process is not as simple in different rhododendron species.

In other varieties, the percentage of rooting was lower; therefore, only more successful hybrid varieties of rhododendrons are presented.

In 2018, experimental work was carried out with 46 varieties of deciduous rhododendrons. Cuttings were taken from the upper half-lignified shoots of this year in mid-June and were divided into control and experimental variants. In the experiment, there were two concentrations of IBA solution $(0.05 \%)$, exposure for 6 hours and IBA solution $(0.01 \%)$, exposure for 16 hours. The cuttings were then planted in the prepared substrate 
and the rooting process was monitored. In the fall, after 3 months, the following results were obtained. When treating cuttings with IBA solution $(0.05 \%)$ in the experimental variant, rooting was observed in the following varieties, and amounted to: 'Juliduft' 100\%, 'Lady Roseberry' - 73.9\%, 'Satomi' - 68.8\%, 'Schneegold' 42.1\%, Golden Eagle $36.2 \%$, Goldpracht $35.7 \%$, Tunis $35.3 \%$, Millenium $32.1 \%$.

When treating cuttings of deciduous rhododendrons with IBA solution $(0.01 \%)$, out of 46 tested varieties, when exposed to stimulants, 27 varieties took root. Top performers were Persil $-100.0 \%$, Hugh Wormald $-100.0 \%$, Jolie Madame $87.5 \%$, Royal Command 86.6\%, Goldpracht $85.7 \%$, Klondyke - 83.3\%, Golden Sunset - 80.6\%, Satomi - $73.5 \%$, Millenium - 73.7\%, My Raini - 69.2\%, Whitetroat 62.8\%, Freya $62.3 \%$ Homebush $61.5 \%$ Golden Eagle 61.5\% Fireball 60.1\% Ramapo 56.3\%, Balzac - 55.5\%, Sun Star - 52.9\%. Jianita - 52.6\%, Azalea pontica - 50.0\%, Tunis - 45.5\%, Juliduft - 45.5\%, Gibraltar $45.3 \%$, Feuerwerk - $40.0 \%$. In other varieties, the percentage of rooting was lower; therefore, only more successful hybrid varieties of rhododendrons are presented. It should be noted that even without treatment, rooting of some varieties was observed in the control variant Juliduft - 38.8\%, Quiet Thought's - 31.2\%, Feuerwerk - 25.5\%, Satomi - 25.0\%, Homebush - 25.0\%, Goldpracht - 24.0\%, Hugh Wormald - 22.0\%, Balzac - 20.8\%, Gibraltar $-20.3 \%$, although the figures were much lower.

In the process of counting rooted cuttings in many varieties, the formation of a powerful callus was found - an influx at the base of the cuttings, but no roots or even their bases were observed (Fig. 1).

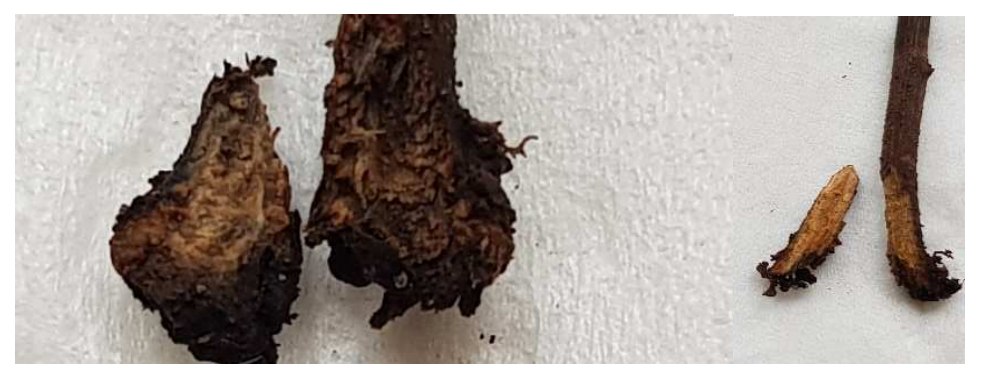

Fig. 1. The appearance of callus in cuttings of rhododendrons

Usually, callus appears under the influence of growth substances and hormones, and then the process of rooting begins. New roots in a cutting come out of the callus or above it from the stem. One of the features of growth substances such as indoleacetic, indole butyric acid and naphthylacetic acids is their stimulating effect on increasing the number and size of cells affected by them. Quite large growths and calli can form on various plant organs if sufficiently high concentrations of these substances are applied. The actions of many of them are not specific, the primary effect is tissue damage, this causes cell changes and indirectly leads to an atypical growth reaction near the wound itself. With no certain conditions, callus does not remain like that indefinitely, but tends to form normally organized structures again. This occurs with the help of new apical meristems of both shoots and roots, which soon appear on it [11]. Depending on the rooting phase of a cutting, the ratio of the air temperature and the substrate should also change. In the first phase of rooting, when root bases are formed in tissues of a cutting, the substrate temperature should be 2-3 degrees higher than the air temperature. During this period, there is an outflow of plastic substances from the upper part to the place of rooting, on the cut, along the cambial ring, a callus is formed. It is fair to assume that a large number of unrooted cuttings, which stopped in their development at the stage of callus formation, is associated with a violation of the relationship between the temperatures of the substrate and the environment [12]. Since the roots of cuttings did not form and new shoots did not 
appear, such cuttings were again planted in boxes and moved to a greenhouse for the winter period.

In 2019, when cutting grafting deciduous rhododendrons, 5 more new varieties were added, the popular Clonex rooting hormone (UK) was used, which includes 4 indol-3-yl butyric acid at a concentration of $3 \%$ and a vitamin complex. The rooting agent is a violetcolored gel, into which the roots of the cuttings rooted were 1-2 cm immersed and planted in a prepared standard substrate. In the fall, after calculating the results of the experiment, it was found that rooting without treating new varieties was weak, is within $10-20 \%$. Treated cuttings took root in 16 varieties of rhododendrons, the best results were for Juliduft - 100\%, Jolie Madame - 50.0\%, Sun Star - 48.8\%, Berry Rose - 30.1\%, Persil $22.5 \%$, Ribbon Candy $-22.0 \%$. The formation of powerful callus at the base of cuttings was also partially observed. There is some suggestion that this could be due to a temperature abuse during the rooting period (drying out of the substrate), since the summer was hot. It should be noted that there are still about 15 varieties of deciduous rhododendrons that died after the first overwintering in film greenhouses. It is planned to continue working with these varieties on the selection of root stimulating agents and conditions for cutting and producing seedlings.

\section{Conclusion}

Out of 50 varieties of deciduous rhododendrons, tested for the ability to vegetative propagation for 3 years, both with the use of various root stimulating agents and without additional treatments, showed the following results. The rooting rate of cuttings in rhododendrons of 32 varieties, on average, ranged from 30 to $100 \%$. Among them, one can single out 22 varieties that are absolutely promising for reproduction and further cultivation, which during the entire experiment had high rooting rates, more than $50 \%$. These are hybrid varieties Satomi, Millenium, Persil, Azalea pontica, Royal Command, Freya, Lady Roseberry, Tunis, Klondyke, Whitetroat, Balzac, Golden Sunset, Jolie Madame, Golden Eagle, My Raini, Hugh Wormald, Goldpracht, Hugh Wormald, Juliduft, Ramapo, Sun Star, Gibraltar.

Analyzing the tested root stimulating agents, one can confidently prefer widely known preparations based on indole butiric and indoleacetic acids. Indole butiric acid at a concentration of $0.01 \%$ solution with an exposure of 16 hours is optimal for the rooting of deciduous rhododendrons. The effect on Clonex gel cuttings requires a more careful study, since it is very effective in the propagation of other ornamental plants, mock oranges, hydrangeas, and vesicles.

Thus, as a result of the work done on vegetative propagation by cuttings of hybrid deciduous rhododendrons of the Knap Hill Hybrid group, certain conclusions can be drawn:

- $\quad$ the following should be strictly observed: the collection timing for half-lignified cuttings at the end of flowering;

- $\quad$ soil (acidity) and temperature conditions when rooting.

For successful rooting, use indole butiric acid and its derivatives at a concentration of $0.01 \%$ with an exposure time of 15-16 hours.

- Of the 50 tested varieties of deciduous rhododendrons, 32 varieties rooted well and in the future, actively develop, and 22 varieties have consistently high rates of cutting rooting.

- The method of propagation of deciduous rhododendrons by cuttings is most promising for growing plants in open ground in climatic conditions of Russia. These varieties of deciduous rhododendrons can successfully replenish collection funds in botanical gardens and nurseries of the country, and with active reproduction and 
popularization, significantly expand the varietal diversity of ornamental plants used for green building and ornamental gardening in the North-West, Central Russia, the Urals and Siberia.

The work was performed within the framework of the project of the MBG RAS (No. 18-118021490111-5).

\section{References}

1. M. Alexandrova, Rhododendrons (Moscow, Fiton+, 2003)

2. R. Kondratovich, Rhododendrons in the Latvian SSR. Biological features of the culture. (Riga, Zinatne, 1981)

3. M. Alexandrova, Garden aristocrats: flowering shrubs (Moscow, Fiton+, 2002)

4. L. Plotnikova, T. Khromova, Reproduction of ligneous plants by cuttings. (Moscow, Nauka, 1981)

5. E. Moiseyeva, T, Baranova, A. Voronin, B. Kuznetsov, Voronezh State University Ecosystems, their optimization and protection, 7 (2012)

6. V. Zorikova, Vegetative propagation of rhododendrons. Plants of the natural flora of Siberia for sustainable construction (Novosibirsk, 1972)

7. F. Mamedov, The rooting ability of summer tree species cuttings in various substrates (Baku, 1966)

8. R. Kondratovich, Rhododendrons: ornamental shrubs promising for the Baltics. In the book Landscaping of cities and towns (Vilnius, 1967)

9. L. Runkova, Phytohormones in the processes of growth and development (Moscow, 1974)

10. R. Turetskaya, F. Polikarpova, Vegetative propagation of plants using growth stimulating agents (Moscow, 1968)

11. E. Sinnot, Plant morphogenesis (Moscow, Foreign Literature Publishing House, 1963)

12. D. Whalley, K. Loach. Sci. Hortic. 6, 1 (1977) 